\title{
Evaluation of Permanent Deformation of Unmodified and Rubber-Reinforced SMA Asphalt Mixtures Using Dynamic Creep Test
}

\author{
Herda Yati Katman, ${ }^{1,2}$ Mohd Rasdan Ibrahim, ${ }^{1}$ Mohamed Rehan Karim, ${ }^{1}$ \\ Nuha Salim Mashaan, ${ }^{1}$ and Suhana Koting ${ }^{1}$ \\ ${ }^{1}$ Department of Civil Engineering, Centre for Transportation Engineering, University of Malaya, 50603 Kuala Lumpur, Malaysia \\ ${ }^{2}$ College of Engineering, Universiti Tenaga Nasional, 43000 Selangor, Malaysia
}

Correspondence should be addressed to Herda Yati Katman; herda@uniten.edu.my

Received 9 December 2014; Accepted 27 January 2015

Academic Editor: Krystyn Van Vliet

Copyright ( $) 2015$ Herda Yati Katman et al. This is an open access article distributed under the Creative Commons Attribution License, which permits unrestricted use, distribution, and reproduction in any medium, provided the original work is properly cited.

\begin{abstract}
This paper presents the evaluation of permanent deformation of rubber-reinforced SMA asphalt mixtures by using dynamic creep test. The effect of trans-polyoctenamer as a cross-linking agent in permanent deformation of rubberized mixtures was also evaluated. Dynamic creep test was conducted at different stress levels $(200 \mathrm{kPa}, 400 \mathrm{kPa})$ and temperatures $\left(40^{\circ} \mathrm{C}, 50^{\circ} \mathrm{C}\right)$. Permanent deformation parameters such as dynamic creep curve, ultimate strain, and creep strain slope (CSS) were used to analyse the results. Finally, the creep behaviour of the specimens was estimated by the Zhou three-stage creep model. The results show that crumb rubber and trans-polyoctenamer significantly affected the parameters especially at high stress and temperatures. Consistent findings were observed for all permanent deformation parameters. Moreover, based on Zhou model, it was concluded that resistance to permanent deformation was improved by application of crumb rubber and trans-polyoctenamer.
\end{abstract}

\section{Introduction}

Mechanical behaviour of asphalt highly depends on ambient temperature due to its viscoelastic properties. Asphalt becomes softer and less viscous as temperature increases. On account of that, asphalt binder becomes more susceptible to adopt permanent deformation and thus accelerates rutting in wheel tracks. Moreover, stress induced by loading is another main parameter that leads to permanent deformation in asphalt pavement.

Rutting is observed as the main distress mechanism typically occurring in countries with high pavement in-service temperature like Malaysia. Malaysia essentially experiences tropical weather with the mean annual air temperature of $28^{\circ} \mathrm{C}$ and maximum air temperature of $45^{\circ} \mathrm{C}$ and the maximum average air temperature during the hottest 7-day period (over the pavement design life) being $38^{\circ} \mathrm{C}$ [1]. Road pavement temperature in Malaysia on the other hand ranges from $20^{\circ} \mathrm{C}$ in the early hours of the day to as high as $60^{\circ} \mathrm{C}$ in midday during a hot day. In addition, overloaded vehicles are very common users of Malaysian roads. In 2008, $27 \%$ or 270,000 out of the one million registered commercial vehicles on the roads in the country were commonly overloaded. Overloading of such with high environmental temperature could cause great damage to pavements and therefore deteriorate pavement performance faster than planned.

Incorporating waste tyre in the pavement can be used to tackle some of the pavement problems as shown by many research studies [2-4]. Due to the benefits offered by crumb rubber, many research works have been implemented on the effects of chemical additives to further increase the performance of rubberized binder. Recent studies have shown that the properties of rubberized binder can be improved by adding substances such as chemical stabilizer, an activation agent, and polymers in which the main function is to activate the rubber asphalt interaction and improve crosslinking. For instance, incorporating trans-polyoctenamer to rubberized binder improves the elastic responses at high 
<smiles>C=CC=CC=C</smiles>

1,3-Butadiene

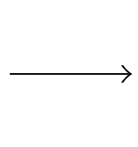

1,5-Cyclooctadien

(COD)
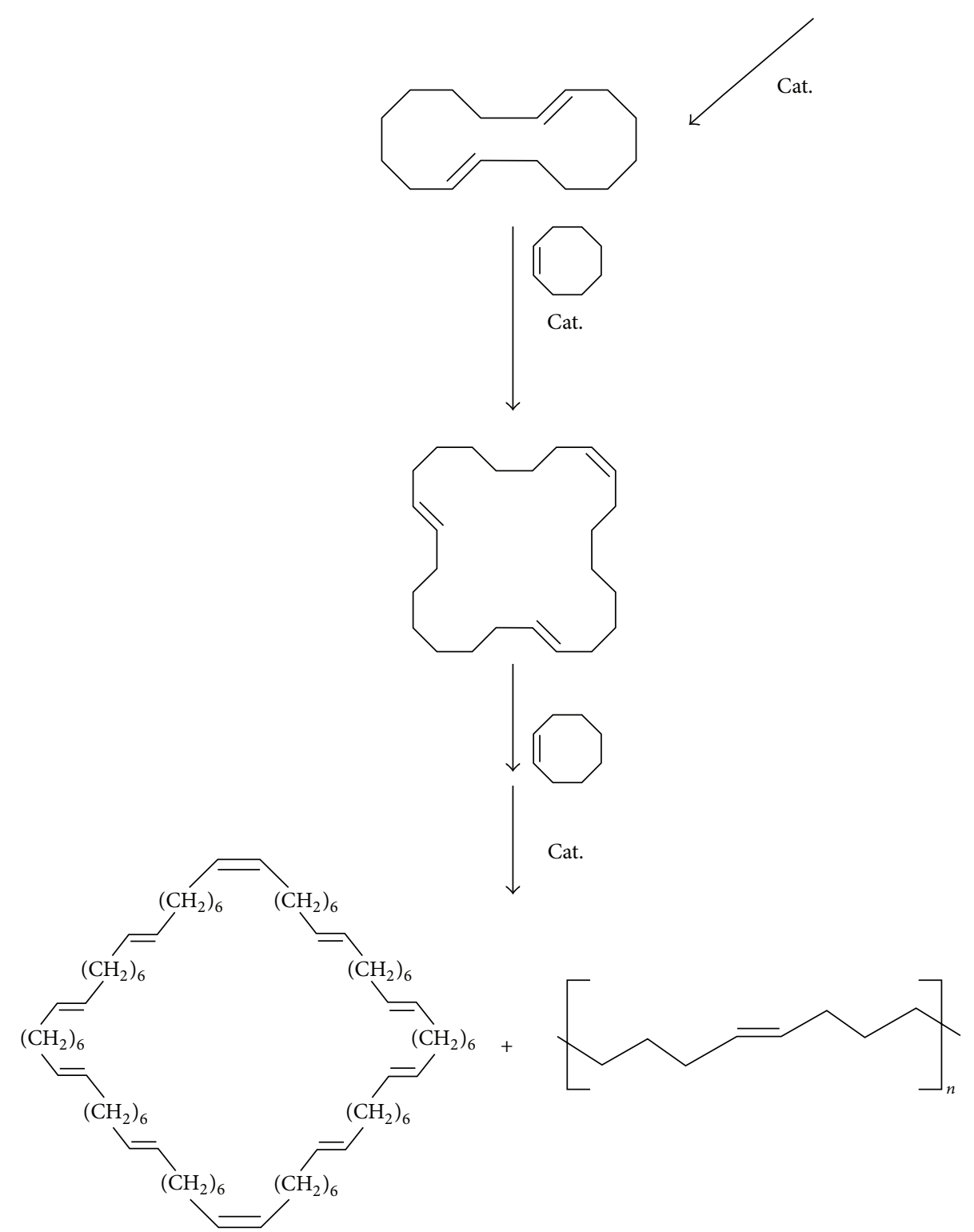

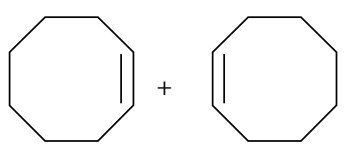

Cyclooctene (COE)

FIGURE 1: Synthesis of trans-polyoctenamer [22].

temperatures and reduced creep stiffness at low temperatures [5]. Therefore this modification reduces the risk of cracking at low temperatures and rutting at high temperatures.

Trans-polyoctenamer is a kind of polymer with a double bond structure, in which the main task is to cross-link the sulphur of the asphaltene and the sulphur on the surface of the crumb rubber to form a ring and mesh composed of chain polymers [6]; thus, it prevents the sinking of the rubber particles by increasing the viscosity. Evonik Degussa $\mathrm{GmbH}$ [7], explained that trans-polyoctenamer chemically bonds to the crumb rubber during its blending and converts the thermoplastic asphalt to a thermoset polymer that can help reduce cracking and rutting. Trans-polyoctenamer is structured of cyclooctene which is synthesized from 1,3butadiene via 1,5-cyclooctadiene. Cyclooctene is polymerized to polyoctenamer that produces both linear and cyclic macromolecules. The molecular formula of polyoctenamer is $-(\mathrm{C} 4 \mathrm{H} 7=\mathrm{C} 4 \mathrm{H} 7)-n$ and its synthesis is shown in Figure 1.

Dynamic creep test performed using such well recognized apparatus like the Universal Testing Machine (UTM), 
TABle 1: Properties of crushed granite aggregate used in this study.

\begin{tabular}{llccc}
\hline Properties & Specification & Results & REAM requirement & Conform \\
\hline Aggregate crushing value & BS812: part 3 & $20 \%$ & $<25 \%$ & $>40 \%$ \\
Polished stone value & BS812: part 3 & 51.7 & $<25 \%$ & Yes \\
Flakiness index value for coarse aggregate & BS182: part 3 & $4 \%$ & $<25 \%$ & Yes \\
Flakiness index value for fine aggregate & BS182: part 3 & $13 \%$ & $<2 \%$ & Yes \\
Water absorption for coarse aggregates & ASTM C 127-88 & $0.586 \%$ & $<2 \%$ & Yes \\
Water absorption for fine aggregates & ASTM C 127-88 & $0.723 \%$ & Yes \\
\hline
\end{tabular}

which provides multiple output data with reasonable test time and less material consumption, seems to be the most popular option to evaluate permanent deformation of asphalt mixtures. To match the real environmental conditions, the influence of different temperature and loading conditions (e.g., frequency, duration, load cycles, and stress level) on permanent deformation can be evaluated and incorporated under UTM. Previous research reported that dynamic creep test had very good correlation with measured rut depth and a high capability to estimate rutting potential of asphalt layers. Research conducted by Kaloush and Witczak [8] mentioned that dynamic creep test is an appropriate laboratory method to investigate the permanent deformation of modified and unmodified asphalt mixtures. Moreover, it is reported by Fontes et al. [9] that results from the dynamic creep tests are so closely correlated with the results of wheel tracking test.

In addition to the laboratory tests, many researchers are interested in developing the performance models to characterize the permanent deformation and further estimate the future pavements' service. As reported by Zhou et al. [10], various mathematical models, among which are well known models such as power-law model, VESYS model, Ohio State model, Superpave, and AASHTO 2002, have been developed for fitting the creep curve and estimating the flow number (FN) parameter in asphalt mixtures. However, these models are limited to describing only the primary stage. West et al. [11] have also developed a three-stage model, but their model cannot estimate the boundary points of curve stages. Therefore, a new three-stage model comparable to the field performance termed as Zhou model [10] is proposed as follows:

$$
\begin{gathered}
\text { Primary stage: } \varepsilon_{p}=a N^{b}, \quad N<N_{P S} \\
\text { Secondary stage: } \varepsilon_{p}=\varepsilon_{P S}+c\left(N-N_{P S}\right), \\
\varepsilon_{P S}=a N_{P S}^{b}, \\
N_{P S} \leq N \leq N_{S T} \\
\text { Tertiary stage: } \varepsilon_{p}=\varepsilon_{S T}+d\left(e^{f\left(N-N_{S T}\right)}-1\right), \\
\varepsilon_{S T}=\varepsilon_{P S}+c\left(N_{S T}-N_{P S}\right), \quad N \geq N_{S T} .
\end{gathered}
$$

Many current research studies used Zhou model to evaluate permanent deformation of unmodified and modified asphalt mixtures [12-14]. It seems that Zhou model outweighs the other model as it can develop mathematical functions to characterize three-stage permanent deformation behaviour of asphalt mixes. Moreover, Zhou model also can be used to identify the transition point between stages especially the new indicator of asphalt mixes: flow number, FN [15].

\section{Objectives and Experimental Procedure}

Due to hot weather with an increase in traffic loading experienced in Malaysia, this study was conducted to investigate the permanent deformation of commonly used aggregate gradation, SMA 20. Effects of crumb rubber as asphalt modifier on permanent deformation characteristics of SMA 20 mixture were also evaluated. To achieve this objective, control and rubberized mixtures were tested for dynamic creep by means of UTM at different stress levels (200 and $400 \mathrm{kPa}$ ) and temperatures $\left(40\right.$ and $\left.50^{\circ} \mathrm{C}\right)$. To further improve performance of rubberized asphalt as well as to study the chemical reactions, trans-polyoctenamer was added. Consequently, test results were analysed to determine the permanent deformation parameters such as dynamic creep curve, ultimate strain, and creep strain slope (CSS). Finally, creep models were derived based on Zhou three-stage model.

\section{Materials and Specimen Preparation}

3.1. Aggregates, Asphalt, Crumb Rubber, and Cross-Linking Agent. Kajang Rock Quarry Sdn. Bhd. located in Kajang, Malaysia, is the supplier of the aggregates. Crushed granite aggregate used in sample preparation is a mixture of coarse aggregate, fine aggregate, and mineral filler sieved from 20-nominal-size aggregate, 10-nominal-size aggregate, and quarry dust. A $2 \%$ Portland cement by weight of the mixtures as proposed under REAM SP 4/2008 is used in all specimens' preparation [16]. Table 1 shows the physical properties of crushed granite aggregate tested in accordance with ASTM international standards (ASTM) and British Standard (BSI) with quality requirement specified by REAM SP 4/2008.

Bitumen grade $80 / 100$ penetration obtained from the vacuum distillation residue derived from crude oil is widely used in Malaysian road construction. In this study, bitumen 80/100 was obtained from Asphalt Technology Sdn. Bhd. located at Port Klang, Malaysia. The basic properties of asphalt including penetration, softening point, and high temperature viscosity tested in accordance with ASTM D 5, ASTM D 36, and ASTM D 4402 are presented in Table 2 [1719]. 
TABLE 2: Basic properties of asphalt and rubberized asphalt.

\begin{tabular}{lccc}
\hline Properties & $\begin{array}{c}\text { Control asphalt } \\
80 / 100 \text { pen }\end{array}$ & \multicolumn{2}{c}{ Rubberized asphalt } \\
& $92 \mathrm{R}$ & 67.50 \\
\hline Penetration $\left(25^{\circ} \mathrm{C}, 100 \mathrm{~g}, 5 \mathrm{~s}\right)(0.01 \mathrm{~mm})$ (ASTM D 5) & 95.00 & 51.00 & 66.29 \\
Softening point (ring and ball) ( $\left.{ }^{\circ} \mathrm{C}\right)(\mathrm{ASTM}$ D 36) & 44.25 & 807.80 & 53.00 \\
Viscosity at $135^{\circ} \mathrm{C}$ (mPa s) (ASTM D 4402) & 375.25 & 997.80 \\
\hline
\end{tabular}

TABLE 3: Specification of crumb rubber used in this study.

\begin{tabular}{lc}
\hline Chemical and physical properties & $\begin{array}{c}\text { Rubber size } \\
30 \text { mesh }\end{array}$ \\
\hline Acetone extract (ISO 1407), \% & $10 \pm 3$ \\
Ash content (ISO), \% & $8 \pm 3$ \\
Carbon black (ISO 1408), \% & $30 \pm 5$ \\
Rubber hydrocarbon (RHC), \% & $52 \pm 5$ \\
Passing (ASTM D5644), \% & $>90$ \\
Heat loss (ASTM D1509), \% & $<1$ \\
Metal content (ASTM D5603), \% & $<1$ \\
Fiber content (ASTM D5603), \% & $<3$ \\
\hline
\end{tabular}

In order to investigate the effect of the crumb rubber on rutting resistance of SMA 20 mixtures, crumb rubber sized 30 mesh $(0.60 \mathrm{~mm})$ supplied by Rubplast $\mathrm{Sdn}$. Bhd. was used in this study. Twelve percent (12\%) of crumb rubber by weight of bitumen $80 / 100$ penetration was used in preparation of rubberized bitumen. Table 3 shows the chemical and physical properties of crumb rubber.

Trans-polyoctenamer bought from Evonik Degussa $\mathrm{GmbH}$, Germany, with the trademark Vestenamer was chosen as a cross-link dispersant, which, along with crumb rubber, might improve the binder performance. The recommended dosage, $4.5 \%$ by weight of crumb rubber, was incorporated into rubberized bitumen [20-22]. Table 4 shows the chemical and physical properties of trans-polyoctenamer, respectively.

\subsection{Mix Design}

3.2.1. Preparation of Rubberized Asphalt. Rubberized asphalt was prepared by adding crumb rubber sized 30 mesh $(0.60 \mathrm{~mm})$ to $80 / 100$ pen asphalt cement. In this study, rubberized asphalt was prepared with $12 \%$ crumb rubber (12R) and $12 \%$ crumb rubber with $4.5 \%$ trans-polyoctenamer $(12 \mathrm{R} 4.5 \mathrm{~V})$. The mixing was done using propeller mixer at speed of $200 \mathrm{rpm}$ for 45 minutes and mixing temperature was maintained at $180^{\circ} \mathrm{C}$. Crumb rubber and transpolyoctenamer were added simultaneously at the beginning of the mixing. For all types of rubberized asphalt, amount of crumb rubber is calculated by weight of the asphalt, while amount of trans-polyoctenamer is calculated by weight of the crumb rubber.

The laboratory produced rubberized asphalt was given identification names. Table 5 presents the binder ID with the matrix for three types of binders developed and evaluated in this study. Control sample designated as control was prepared with bitumen $80 / 100$ penetration. 12R stands for rubberized

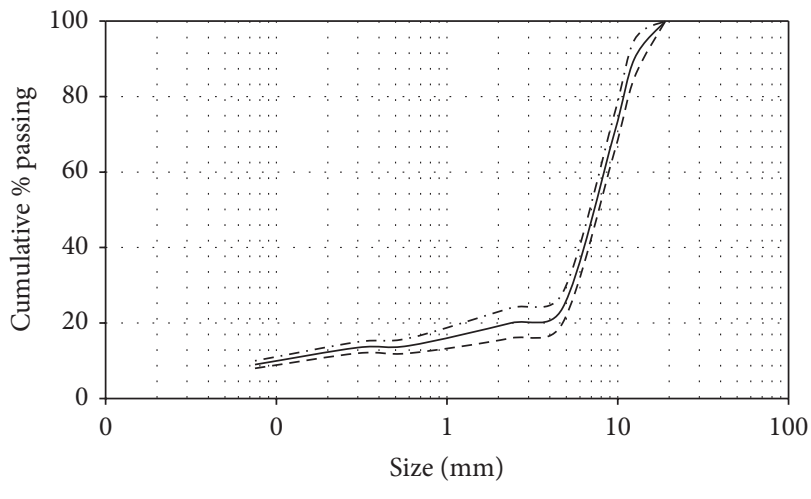

$$
\begin{aligned}
& \text { _ Mid-pt } \\
& \text { - - Lower limit } \\
& \text { _.- } \text { Upper limit }
\end{aligned}
$$

FIGURE 2: SMA 20 aggregate gradation.

asphalt prepared with $12 \%$ of crumb rubber (by weight of $80 / 100$ penetration bitumen), whereas $12 \mathrm{R} 4.5 \mathrm{~V}$ is rubberized asphalt prepared with $12 \%$ crumb rubber (by weight of bitumen $80 / 100$ penetration) and $4.5 \%$ trans-polyoctenamer (by weight of crumb rubber).

3.2.2. Preparation of Specimen. In this study SMA 20 aggregate gradation as shown in Figure 2 was used in preparation of all specimens. Optimum asphalt content determined by Marshall method was used. It was determined that optimum asphalt content for control specimen is $5.0 \%$, whereas $5.5 \%$ is the optimum asphalt content for specimens prepared with $12 \mathrm{R}$ and $12 \mathrm{R} 4.5 \mathrm{~V}$ binder. Table 6 shows the mix design of specimens evaluated in this study. The same designations were also used in specimen prepared from the respective binders.

Each specimen comprised $1100 \mathrm{~g}$ of aggregates and $2 \%$ of Portland cement by weight of the mix. Aggregate and cement were heated in the oven for one hour at $150^{\circ} \mathrm{C}$. Aggregate was then transferred to the pan and heated at higher temperature of $170^{\circ} \mathrm{C}$. The rubberized asphalt $(12 \mathrm{R}$ and $12 \mathrm{R} 4.5 \mathrm{~V})$ at optimum content was added to the aggregate and mixed at $170^{\circ} \mathrm{C}$ until all aggregates were fully coated with the binder. Mixture was then transferred to the Marshall mould and was spaded 15 times around the parameter and 10 times over the interior. Mixture was compacted by applying 50 blows for both sides with the Marshall compactor when temperature reached $140^{\circ} \mathrm{C}$. After compaction, the mould was removed from the base-plate; the specimen was cured for 24 hours in the mould at room temperature before extruding it by means 
TABLE 4: Specification of trans-polyoctenamer used in this study.

\begin{tabular}{|c|c|c|c|c|}
\hline Property & & Test method & Unit & Value \\
\hline Molecular weight $M_{w}$ & GPC & DIN 55672-1 & - & 90,000 \\
\hline Glass transition temperature & $\mathrm{Tg}$ & ISO 11357 & ${ }^{\circ} \mathrm{C}$ & -65 \\
\hline Crystallinity & $23^{\circ} \mathrm{C}$ & ISO 11357 & $\%$ & 30 \\
\hline Melting point & $\begin{array}{c}\text { DSC } \\
\text { 2nd heating }\end{array}$ & ISO 11357 & ${ }^{\circ} \mathrm{C}$ & 54 \\
\hline Apparent density & $23^{\circ} \mathrm{C}$ & ISO 60 & $\mathrm{~g} / \mathrm{l}$ & 560 \\
\hline Density & $23^{\circ} \mathrm{C}$ & ISO 1183 & $\mathrm{~g} / \mathrm{cm}^{3}$ & 0.91 \\
\hline \multicolumn{5}{|l|}{ Tensile test } \\
\hline Stress at yield & & & $\mathrm{MPa}$ & 7.5 \\
\hline Strain at yield & & ISO $527-1 /-2$ & $\%$ & 25 \\
\hline Strain at break & & & $\%$ & 400 \\
\hline \multirow{3}{*}{ Tensile impact strength } & $23^{\circ} \mathrm{C}$ & \multirow{3}{*}{ ISO 8256} & $\mathrm{~kJ} / \mathrm{m}^{2}$ & 165 \\
\hline & $0^{\circ} \mathrm{C}$ & & $\mathrm{kJ} / \mathrm{m}^{2}$ & 190 \\
\hline & $-20^{\circ} \mathrm{C}$ & & $\mathrm{kJ} / \mathrm{m}^{2}$ & 240 \\
\hline
\end{tabular}

TABle 5: Matrix of binders developed.

\begin{tabular}{lccc}
\hline $\begin{array}{l}\text { Base bitumen } \\
80 / 100 \text { penetration }\end{array}$ & $\begin{array}{c}\text { Rubber content, } \\
\%\end{array}$ & \multicolumn{2}{c}{ Trans-polyoctenamer, } \\
$\%$ & \\
Binder ID & & 0 & 4.5 \\
\hline Control & 0 & $\checkmark$ & \\
$12 \mathrm{R}$ & 12 & $\checkmark$ & \\
$12 \mathrm{R} 4.5 \mathrm{~V}$ & 12 & & $\checkmark$ \\
\hline
\end{tabular}

TABLE 6: Mix design of specimens.

\begin{tabular}{lcc}
\hline Specimens ID & $\begin{array}{c}\text { Optimum asphalt } \\
\text { content, \% }\end{array}$ & Binder used \\
\hline Control & 5.0 & Bitumen $80 / 100$ pen. \\
$12 \mathrm{R}$ & 5.5 & $12 \mathrm{R}$ \\
$12 \mathrm{R} 4.5 \mathrm{~V}$ & 5.5 & $12 \mathrm{R} 4.5 \mathrm{~V}$ \\
\hline
\end{tabular}

of an extrusion jack. Similar procedure was followed for preparation of control specimen except mixing temperature was done at $150^{\circ} \mathrm{C}$ and compacted at $135^{\circ} \mathrm{C}$.

\section{Creep Test}

Maximum particle size of aggregate in the mixtures is $19 \mathrm{~mm}$ $(\leq 20 \mathrm{~mm})$; therefore specimens were trimmed at top and bottom side with a diamond saw to the final thickness of $50 \mathrm{~mm}$. Both sides of each sample were coated with a thin layer of silicone grease containing graphite flakes in order to obtain smooth faces. This is to eliminate the influence of unevenness of specimen face which would affect the test results.

The repeated creep test was performed using Universal Testing Machine (UTM). It is the most commonly used device to measure the permanent deformation of asphalt mixture in laboratory. Specimen will be placed in the temperature controlled cabinet for 2 hours to ensure that equilibrium temperature is reached. Specimen was then placed between the platens. The assembled platens and specimen were aligned concentrically with the loading axis of the testing machine. The displacement measuring device is then attached to the platens. The vertical deformation is then measured by the linear variable differential transducers (LVDTs). In this study, the loading parameters consisted of a haversine wave shape with two stress levels of $200 \mathrm{kPa}$ and $400 \mathrm{kPa}$ and in addition two test temperatures of $40^{\circ} \mathrm{C}$ and $50^{\circ} \mathrm{C}$ were selected. The load was applied for $0.5 \mathrm{~s}$ followed by a rest period of $1.5 \mathrm{~s}$. The specimen was terminated after 1800 load cycles or until accumulated strain reaches $100,000 \mu \mathrm{s}$. The accumulated strain was calculated by using the following equation:

$$
\varepsilon=\frac{h}{H_{0}},
$$

where $\varepsilon$ is the accumulated strain, $h$ is the axial deformation, $\mathrm{mm}$, and $H_{0}$ is the initial specimen height, $\mathrm{mm}$.

\section{Result and Analysis}

5.1. Dynamic Creep Curve. After testing, dynamic creep curves of all specimens were obtained. These data are depicted in Figures 3(a)-3(d). It can be found that there are significant differences among these curves. Each dynamic creep curve consists of two parts, namely, primary stage and secondary stage. Primary stage presents recoverable elastic strain due to densification of the mixture while secondary stage shows viscoelastic strain resulted by cumulative axial strain [23]. In this test, tertiary stage of specimen did not occur due to a short loading period of 1800 cycles except for control mixture tested at $400 \mathrm{kPa}$ stress level and $50^{\circ} \mathrm{C}$.

Higher accumulated axial strains values indicate that mixes have lower rutting resistance potential. It is apparent that specimens prepared with rubberized asphalt show a lower cumulative permanent strain compared to control specimen as seen in Figures 3(a)-3(d). This is because crumb rubber which has partially digested into the asphalt absorbs 


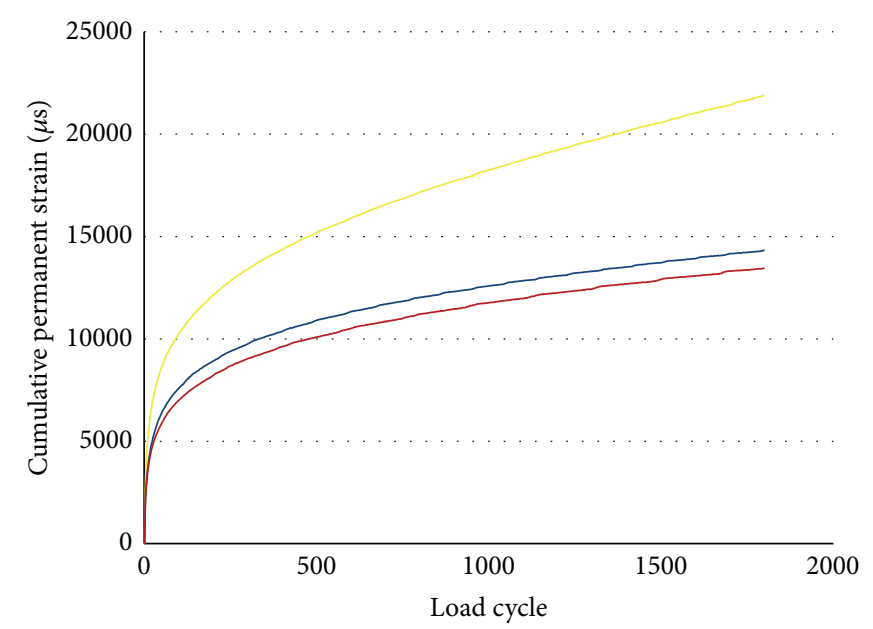

(a)

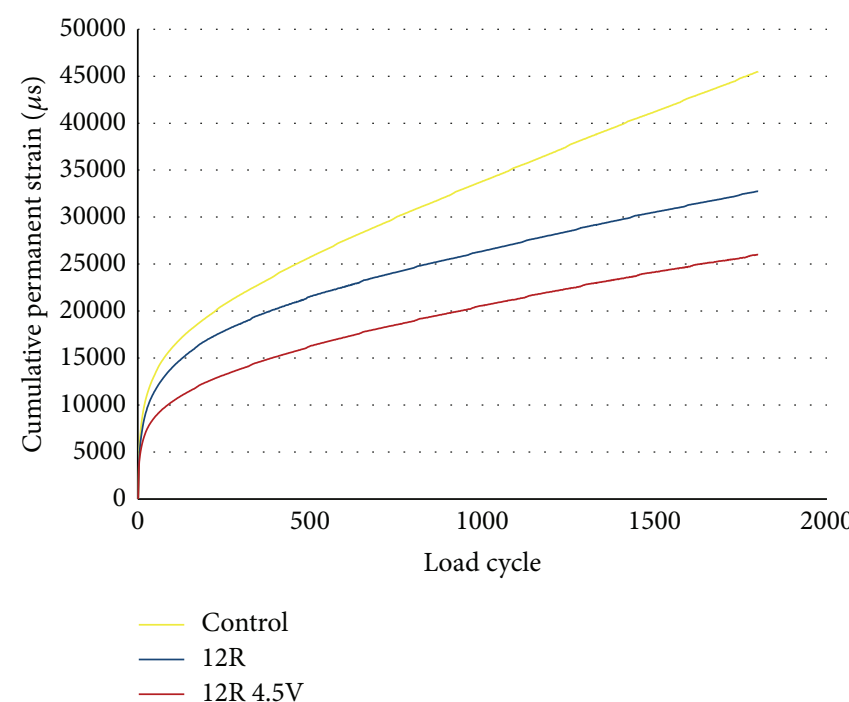

(c)

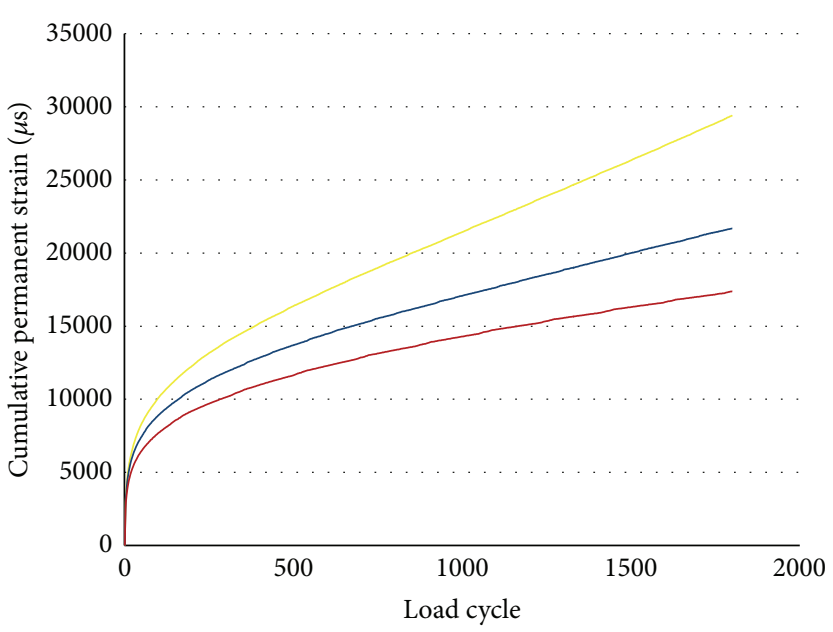

(b)

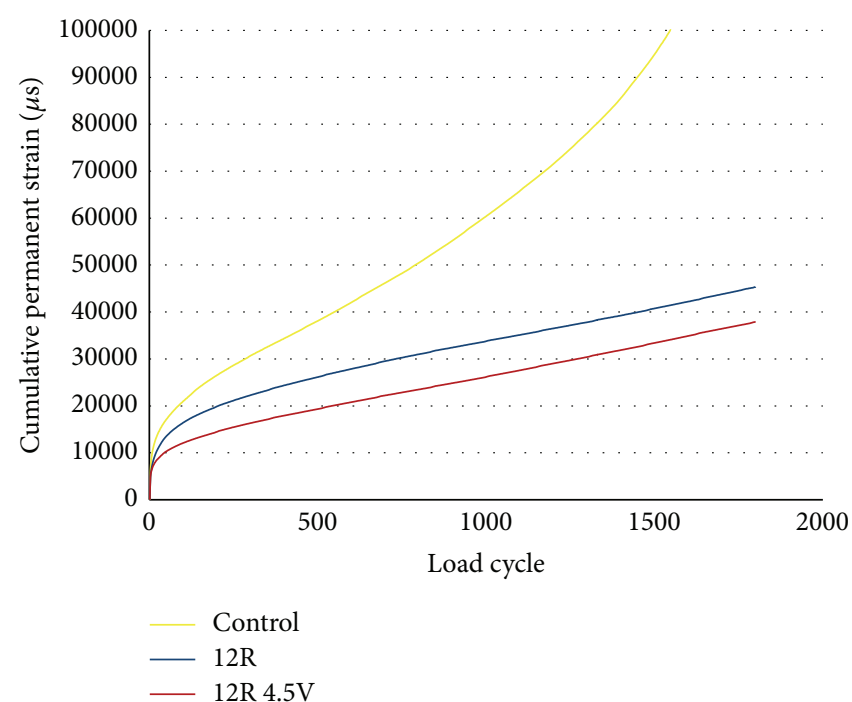

(d)

Figure 3: Cumulative permanent strain versus load cycle for control and rubberized mixtures tested at (a) $200 \mathrm{kPa}$ at $40^{\circ} \mathrm{C},(\mathrm{b}) 200 \mathrm{kPa}$ at $50^{\circ} \mathrm{C}$, (c) $400 \mathrm{kPa}$ at $40^{\circ} \mathrm{C}$, and (d) $400 \mathrm{kPa}$ at $50^{\circ} \mathrm{C}$.

the aromatic oils from the asphalt into the rubber's polymer chains. It implies the formation of gel-like material that results in higher viscosity and elasticity of the asphalt. Such interactions improve the binder networking and allow greater film thickness surrounding the aggregate in the mixture. This will reinforce the aggregate bonding of the mixtures thus resulting in higher strength. Furthermore, the crumb rubber which is not digested in the asphalt will maintain their integrity, interweave together, and form a three-directional network when distributed uniformly in the mixtures. This spatial reinforcing network could reinforce the mixtures and resist damage propagation.

As can be seen in Figures 3(a)-3(d), incorporating transpolyoctenamer as a cross-link dispersant agent in preparation of rubberized binder indicates a significant enhancement in the behaviour of mixtures as showed by $12 \mathrm{R} 4.5 \mathrm{~V}$ mixtures. This implies that trans-polyoctenamer improves the rheological properties of rubberized binder by activating the crumb rubber and asphalt to form a chemical reaction. The reaction permits cross-linking with the sulfur associated with the asphaltenes and maltenes in the asphalt to create a macropolymer network. Finally, a uniform, low tack, rubber-like composite is produced which is capable of improving the rutting resistance of the mixtures [24].

5.2. Ultimate Strain. Results of ultimate strain after 1800 load cycles are illustrated in Figure 4. As can be seen in the figure, the ultimate strain of rubberized mixtures improves remarkably compared to the control mixtures. In all test conditions, specimens prepared with $12 \mathrm{R} 4.5 \mathrm{~V}$ show the lowest ultimate strain followed by $12 \mathrm{R}$ and control mixture. It implies that incorporating crumb rubber and trans-polyoctenamer in asphalt provides significant impact on susceptibility of mixtures to permanent deformation. 


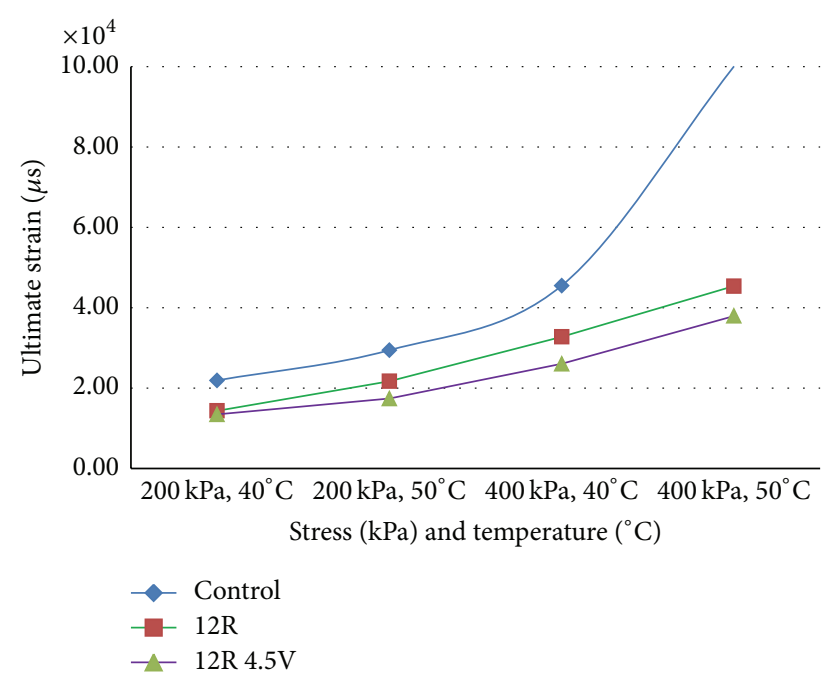

FIGURE 4: Ultimate strains for control and rubberized mixtures at different stress level and temperature.

It is important to note that the ultimate strain increases at higher temperature. For instance, at $200 \mathrm{kPa}$ stress, in case of control mixture when the temperature increases from $40^{\circ} \mathrm{C}$ to $50^{\circ} \mathrm{C}$, the strain value rises from $21901.06 \mu \mathrm{s}$ to $29418.91 \mu \mathrm{s}$ which is 1.34 times higher in comparison with $40^{\circ} \mathrm{C}$. However, dependency of ultimate strain on temperature in rubberized mixtures is considerably lower than that of control mixtures, especially specimen with addition of trans-polyoctenamer. For example, at stress level $200 \mathrm{kPa}$ and $400 \mathrm{kPa}$, increase in $10^{\circ} \mathrm{C}$ (from $40^{\circ} \mathrm{C}$ to $50^{\circ} \mathrm{C}$ ) the ultimate strain for control mixture increases 1.34 and 2.20 times, while $12 \mathrm{R} 4.5 \mathrm{~V}$ rises at lower rates compared to control mixture that is, 1.29 and 1.46 times, respectively.

The similar trend was observed by rising stress level in which the ultimate strain increases by an increment in stress (from $200 \mathrm{kPa}$ to $400 \mathrm{kPa}$ ) for both $40^{\circ} \mathrm{C}$ and $50^{\circ} \mathrm{C}$ temperatures. In control mixtures, the rate of increment is more than rubberized mixtures. Results show that the ultimate strain increased 3.40, 2.09, and 2.18 times for control, $12 \mathrm{R}$, and $12 \mathrm{R} 4.5 \mathrm{~V}$, respectively, as stress increased from $200 \mathrm{kPa}$ to $400 \mathrm{kPa}$ at $50^{\circ} \mathrm{C}$. This means that control mixtures deform more than three times while rubberized mixtures show better resistance to deformation as stress increases.

Moreover, control mixture deforms very fast at highest test condition $\left(400 \mathrm{kPa}, 50^{\circ} \mathrm{C}\right)$. In other words, increase in stress and temperature has caused a dramatic growth in the ultimate strain of control mixtures so that these samples faced a total destruction of $100,000 \mu$ s. On the contrary, in the rubberized mixtures, the ultimate strain is much lower which is $45359.73 \mu$ s and $37915.94 \mu$ s for $12 \mathrm{R}$ and $12 \mathrm{R} 4.5 \mathrm{~V}$, respectively, which is equivalent to 2.20 and 2.64 times less compared to control mixture. Thus, efficiency of crumb rubber was clearly observed at highest test condition which the rubberized mixtures deform much lower compared to control mixture.

5.3. Creep Strain Slope (CSS). CSS is the slope of the secondary phase of typical repeated load creep test results.

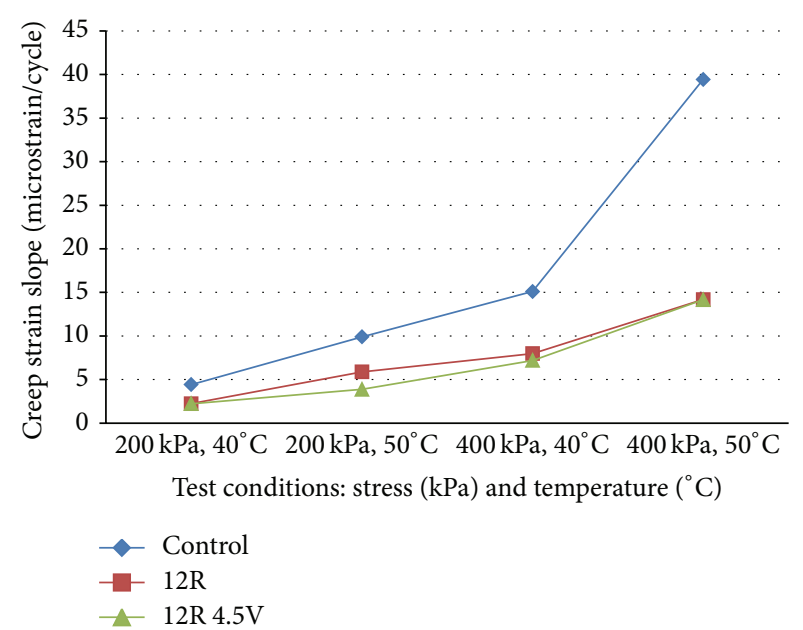

FIGURE 5: CSS results for control and rubberized mixtures versus test conditions.

It is calculated from the regression line that excludes the primary stage and therefore perfectly reflects the rate of deformation affected by the load cycling. For constant stress loading conditions, the creep strain rate is approximately constant during the secondary creep phase. Hence, CSS is another permanent deformation characteristic that shows the developing rate of deformation $[25,26]$.

Figure 5 shows the CSS results for control and rubberized mixtures under different stress level and temperature. Similar to ultimate strain results, Figure 5 manifests that modifying asphalt mixtures with rubber and trans-polyoctenamer decreases the temperature and stress susceptibility of the mixtures. In other words, dependency of permanent deformation on temperature and stress in rubberized mixtures is considerably lower than that of control mixture.

As seen in Figure 5, increasing the temperature from $40^{\circ} \mathrm{C}$ to $50^{\circ} \mathrm{C}$ at stress level of $200 \mathrm{kPa}$ in control mixtures increases the CSS 2.24 times (from 4.42 to 9.90). Moreover, at stress level of $400 \mathrm{kPa}, 10^{\circ} \mathrm{C}$ increase in temperature results in rises CSS 2.61 times (from 15.10 to 39.44) for control mixture. However, in rubberized mixtures at $200 \mathrm{kPa}$ and $400 \mathrm{kPa}$ stress level, an increase $10^{\circ} \mathrm{C}$ in temperature can lead to 1.74 times and 1.97 times increase, respectively (from 2.22 to 3.87 and from 7.19 to 14.16 ), considerably lower than control mixture. Rubberized mixtures at both stress levels, therefore, are less sensitive to temperature increase than control mixture.

Further, by rising stress level, the same finding was observed. Increase in load stress leads to increase in CSS for all mixtures. Result obtained by control mixture shows that increasing the stress level from $200 \mathrm{kPa}$ to $400 \mathrm{kPa}$ at $40^{\circ} \mathrm{C}$ rises the CSS around 3.42 times (from 4.42 to 15.10 ) and 3.98 times ( 9.90 to 39.44 ) at $50^{\circ} \mathrm{C}$. CSS for rubberized mixtures also increases as stress level increases; however the rate is lower compared to control mixture. For instance, at the same test condition as above, the CSS for rubberized mixtures increases 3.24 times (from 2.22 to 7.19 ) and 3.66 times (from 3.87 to 14.16 ), which is slightly lower than the control mixture. 


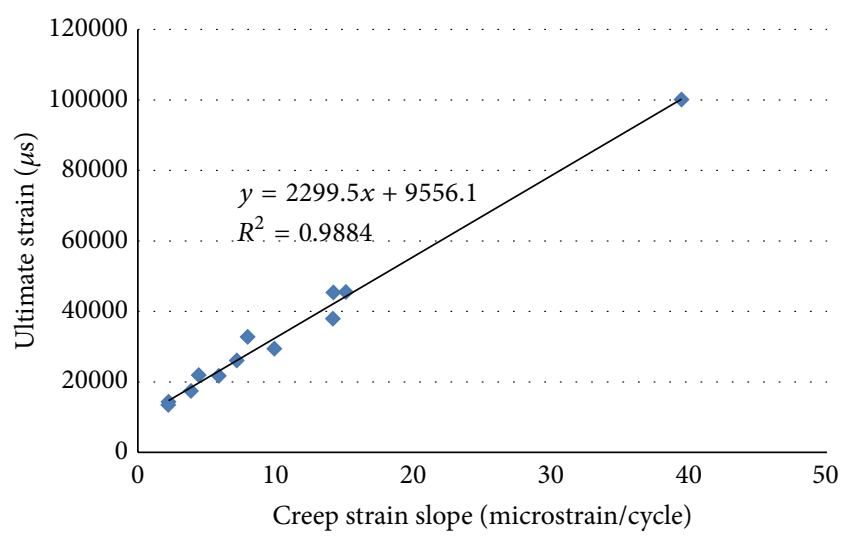

FIGURE 6: Ultimate strain versus creep strain slope for control and rubberized mixtures.

The above findings show that the rubberized mixtures are less susceptible to stress level compared to control mixture.

It is important to note that comparison of CSS between control and rubberized mixtures becomes more significant as stress level and temperature increase. For instance, the rate of CSS for control mixtures is 1.99, 2.56, 2.10, and 2.78 times that of the $12 \mathrm{R} 4.5 \mathrm{~V}$ for $200 \mathrm{kPa}, 40^{\circ} \mathrm{C} ; 200 \mathrm{kPa}, 50^{\circ} \mathrm{C}$; $400 \mathrm{kPa}, 40^{\circ} \mathrm{C}$; and $400 \mathrm{kPa}, 50^{\circ} \mathrm{C}$, respectively. However, it seems that low temperature and low stress level did not reveal the benefits of rubberized asphalt. Above phenomenon is probably due to the behaviour of crumb rubber particles that do not dissolve entirely in asphalt; it swells and adsorbs the certain components of the asphalt. Therefore the crumb rubber maintains their integrity and acts as flexible filler in the mixtures. At high temperature, the crumb rubber is stiffer than the asphalt while at low temperature the asphalt is stiffer whereas the crumb rubber properties do not change significantly. Thus, at low temperature and stress level, the strength of mixture is not attributable to the role of rubberized binder but rather more to the contact points in the aggregate skeleton. As seen in Figure 5, at $200 \mathrm{kPa}$ stress level and $40^{\circ} \mathrm{C}$ temperature, the CSS for all mixtures is not much different; thus it supported above justification.

Relationship between ultimate strain and CSS is shown in Figure 6. There is a good correlation between these two parameters. The relationship coefficient of the fitted curve, $R^{2}$, is 0.9884 . It is apparent that ultimate strain increases with an increase of CSS. Therefore if the creep strain slope of the mix is being enhanced; then its susceptibility to permanent deformation will increase as the consequence. Thus ultimate strain and CSS are considered to be useful parameters for evaluating the permanent deformation susceptibility of the mixtures.

\section{Zhou Three-Stage Model}

In this study, Zhou three-stage model was used for better understanding of permanent deformation behaviour of the mixtures. Regression analysis as explained by Zhou et al. [10] was utilized to determine the mathematical functions as

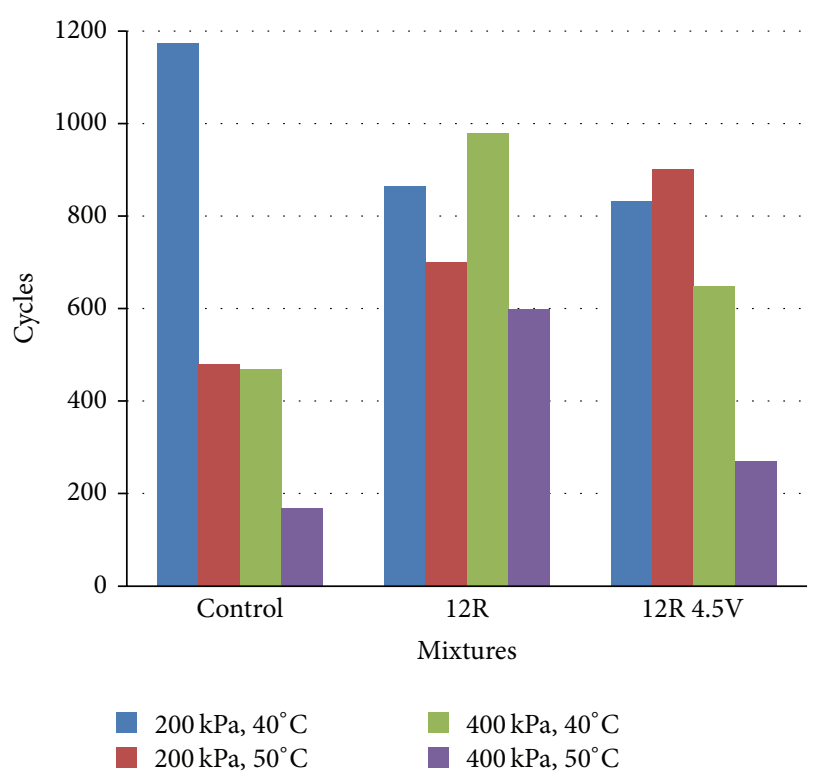

Figure 7: Number of load cycles at first stage for control and rubberized mixtures at all test conditions.

well as transition points between each stage and use it for modelling each stage.

The results are presented in Tables 7 and 8. Achieved results show that all curves obey the Zhou model. Similar strain values are observed when predicted strains calculated via mathematical functions based on Zhou model were comparable with measured strain.

As seen in Tables 7 and 8, results show that control and rubberized mixtures only achieve the secondary stage. This is due to short loading cycles (1800); tertiary stage was not achieved. However, at $400 \mathrm{kPa}$ stress and $50^{\circ} \mathrm{C}$, the control mixtures enter the tertiary stage after 829 loading cycles whereas the rubberized mixtures are still at the second stage.

Figure 7 shows number of load cycles at first stage also known as transition point from first stage to second stage for all mixtures. Generally, the number of load cycles decreases as stress level and temperature increase. As first stage presents recoverable elastic and second stage presents viscoelastic behaviour of the mixture, it means that specimen changes to viscoelastic behaviour faster as stress level and temperature increase. At $40^{\circ} \mathrm{C}$, for instance, increasing stress level from $200 \mathrm{kPa}$ to $400 \mathrm{kPa}$ leads the control mixture to enter the second stage from 1173 cycles to 469 cycles which is 2.5 times faster.

From Figure 7, it can be illustrated that length of first stage for rubberized mixture is longer than control mixture. This shows that rubberized mixtures sustain the first stage longer compared to control mixture. For example, at $400 \mathrm{kPa}$ and $40^{\circ} \mathrm{C}$, transition point for $12 \mathrm{R}$ mixture is 979 cycles while control mixture is 469 cycles which is more than two times longer. Although the length of first stage of modified mixtures is generally longer than control mixture, exception is observed at low test condition $(200 \mathrm{kPa}$ stress level and $40^{\circ} \mathrm{C}$ temperature). 
TABLE 7: Three-stage models and boundary points for control and modified mixtures at $200 \mathrm{kPa}$ stress.

\begin{tabular}{|c|c|c|c|c|c|c|c|c|}
\hline \multirow{2}{*}{$\begin{array}{l}\text { Test } \\
\text { temperature }\end{array}$} & \multirow{2}{*}{ Sample } & \multicolumn{4}{|c|}{ Primary stage } & \multicolumn{2}{|c|}{ Secondary stage } & \multirow{2}{*}{$\begin{array}{c}\text { Tertiary } \\
\text { stage } \\
\text { Model }\end{array}$} \\
\hline & & Model & End point & $\begin{array}{l}\text { Measured } \\
\text { strain, } \mu \mathrm{s}\end{array}$ & $\begin{array}{l}\text { Predicted } \\
\text { strain, } \mu \mathrm{s}\end{array}$ & Model & $\begin{array}{l}\text { End } \\
\text { point }\end{array}$ & \\
\hline \multirow{3}{*}{$40^{\circ} \mathrm{C}$} & Control & $\varepsilon_{P}=2979.3 N^{0.2628}$ & $N=1173$ & 19100.08 & 19086.48 & $\begin{array}{c}\varepsilon_{P}=19086.48+4.422 \\
(N-1173)\end{array}$ & $\mathrm{a}$ & $\mathrm{a}$ \\
\hline & $12 \mathrm{R}$ & $\varepsilon_{P}=2331.3 N^{0.2486}$ & $N=865$ & 12222.56 & 12523.92 & $\begin{array}{c}\varepsilon_{P}=12523.92+2.235 \\
(N-865)\end{array}$ & a & $\mathrm{a}$ \\
\hline & $12 \mathrm{R} 4.5 \mathrm{~V}$ & $\varepsilon_{P}=2169.4 N^{0.248}$ & $N=831$ & 11294.98 & 11492.13 & $\begin{array}{c}\varepsilon_{P}=11492.13+2.223 \\
(N-831)\end{array}$ & $\mathrm{a}$ & $\mathrm{a}$ \\
\hline \multirow{3}{*}{$50^{\circ} \mathrm{C}$} & Control & $\varepsilon_{P}=2513.8 N^{0.3004}$ & $N=479$ & 16116.79 & 16051.05 & $\begin{array}{c}\varepsilon_{P}=16051.05+9.904 \\
(N-479)\end{array}$ & a & a \\
\hline & $12 \mathrm{R}$ & $\varepsilon_{P}=2505.7 N^{0.2737}$ & $N=701$ & 15183.12 & 15059.21 & $\begin{array}{c}\varepsilon_{P}=15059.21+5.886 \\
(N-701)\end{array}$ & a & $\mathrm{a}$ \\
\hline & $12 \mathrm{R} 4.5 \mathrm{~V}$ & $\varepsilon_{P}=2227.5 N^{0.2673}$ & $N=901$ & 13865.05 & 13728.26 & $\begin{array}{c}\varepsilon_{P}=13728.26+3.865 \\
(N-901)\end{array}$ & $\mathrm{a}$ & $\mathrm{a}$ \\
\hline
\end{tabular}

${ }^{\mathrm{a}}$ Not found at the end of 1800 load cycle.

TABLE 8: Three-stage models and boundary points for control and modified mixtures at $400 \mathrm{kPa}$ stress.

\begin{tabular}{|c|c|c|c|c|c|c|c|c|}
\hline \multirow{2}{*}{$\begin{array}{l}\text { Test } \\
\text { temperature }\end{array}$} & \multirow[b]{2}{*}{ Sample } & \multicolumn{4}{|c|}{ Primary stage } & \multicolumn{2}{|c|}{ Secondary stage } & \multirow{2}{*}{$\begin{array}{c}\text { Tertiary stage } \\
\text { Model }\end{array}$} \\
\hline & & Model & $\begin{array}{l}\text { End } \\
\text { point }\end{array}$ & $\begin{array}{l}\text { Measured } \\
\text { strain, } \mu \mathrm{s}\end{array}$ & $\begin{array}{l}\text { Predicted } \\
\text { strain, } \mu \mathrm{s}\end{array}$ & Model & $\begin{array}{l}\text { End } \\
\text { point }\end{array}$ & \\
\hline \multirow{3}{*}{$40^{\circ} \mathrm{C}$} & Control & $\varepsilon_{P}=4088 N^{0.2949}$ & $N=469$ & 25185.27 & 25074.93 & $\begin{array}{c}\varepsilon_{P}=25074.93+15.1 \\
(N-469)\end{array}$ & $\mathrm{a}$ & a \\
\hline & $12 \mathrm{R}$ & $\varepsilon_{P}=3740.9 N^{0.2823}$ & $N=979$ & 26216.27 & 26138.10 & $\begin{array}{c}\varepsilon_{P}=26138.10+7.977 \\
(N-979)\end{array}$ & a & a \\
\hline & $12 \mathrm{R} 4.5 \mathrm{~V}$ & $\varepsilon_{P}=2891.4 N^{0.277}$ & $N=647$ & 17659.15 & 17367.15 & $\begin{aligned} \varepsilon_{P}= & 17367.15+7.19 \\
& (N-647)\end{aligned}$ & a & a \\
\hline \multirow{3}{*}{$50^{\circ} \mathrm{C}$} & Control & $\varepsilon_{P}=5146.9 N^{0.307}$ & $N=169$ & 25046.38 & 24860.33 & $\begin{array}{c}\varepsilon_{P}=24860.33+39.439 \\
(N-169)\end{array}$ & $N=829$ & $\begin{array}{c}\varepsilon_{P}=50890.1+ \\
2789.6\left(e^{0.0046(N-829)}-1\right)\end{array}$ \\
\hline & $12 \mathrm{R}$ & $\varepsilon_{P}=4100.3 N^{0.2983}$ & $N=599$ & 27859.29 & 27626.26 & $\begin{array}{c}\varepsilon_{P}=27626.26+14.184 \\
(N-599)\end{array}$ & a & a \\
\hline & $12 \mathrm{R} 4.5 \mathrm{~V}$ & $\varepsilon_{P}=3923.8 N^{0.2462}$ & $N=269$ & 15792.31 & 15556.50 & $\begin{array}{c}\varepsilon_{P}=15556.5+14.162 \\
(N-269)\end{array}$ & $\mathrm{a}$ & a \\
\hline
\end{tabular}

${ }^{\mathrm{a}}$ Not found at the end of 1800 load cycle.

\section{Statistical Analysis}

Statistical analysis was performed using SPSS software to analyse the relationships between permanent deformation of the mixtures and the parameters. The two-way analysis of variance (ANOVA) was used with a confidence interval of 95\% ( $\alpha=0.05)$. To present permanent deformation of the mixtures, ultimate strain was selected as dependent variable while temperature, stress, and additive (rubber and transpolyoctenamer) were selected as independent variables. The result of two-way ANOVA is tabulated in Table 9, which indicates that temperatures, stress, and additive have a significant effect on the ultimate strain when the $P$ value is less than 0.05 . The interaction effect between the chosen parameters also has a significant effect on the ultimate strain.

\section{Conclusion and Recommendations}

Based on the findings, use of crumb rubber in construction of pavement deserves serious consideration as it significantly improves the resistance to deformation compared to unmodified mixtures. The effect of crumb rubber is more significant at high stress and temperature. This fits in with Malaysia's conditions which observe tropical weather and high traffic volume. Moreover, addition of trans-polyoctenamer increases the resistance to deformation of rubberized mixtures.

Conclusion has been drawn as follows.

(1) Trans-polyoctenamer improves the properties of rubberized asphalt as best resistance to permanent deformation shown by $12 \mathrm{R} 4.5 \mathrm{~V}$ at all test conditions.

(2) At higher stress level and temperature, permanent deformation resistance of both control and rubberized mixtures decreased.

(3) Methods to analyse the permanent deformation by dynamic creep curve, ultimate strain, and CSS are consistent. 
TABLE 9: Two-way ANOVA on ultimate strain.

\begin{tabular}{|c|c|c|c|c|c|}
\hline Source & SS & $\mathrm{df}$ & MS & $F$ & $P$ value \\
\hline Corrected model & $1.727 E 10$ & 11 & $1.570 E 9$ & 575.347 & 0.000 \\
\hline Intercept & $3.410 E 10$ & 1 & $3.410 E 10$ & 12495.654 & 0.000 \\
\hline Stress & $6.012 E 9$ & 1 & $6.012 E 9$ & 2203.268 & 0.000 \\
\hline Temperature & $2.126 E 9$ & 1 & $2.126 E 9$ & 779.059 & 0.000 \\
\hline Additive & $3.795 E 9$ & 2 & $1.897 E 9$ & 695.332 & 0.000 \\
\hline Stress $*$ temperature & $8.442 E 8$ & 1 & $8.442 E 8$ & 309.402 & 0.000 \\
\hline Stress $*$ additive & $1.361 E 9$ & 2 & $6.806 E 8$ & 249.424 & 0.000 \\
\hline Temperature $*$ additive & $8.831 E 8$ & 2 & $4.416 E 8$ & 161.829 & 0.000 \\
\hline Stress $*$ temperature $*$ additive & $7.231 E 8$ & 2 & $3.616 E 8$ & 132.513 & 0.000 \\
\hline Error & $5.457 E 7$ & 20 & 2728588.943 & & \\
\hline Total & $5.663 E 10$ & 32 & & & \\
\hline
\end{tabular}

a. $R$ Squared $=0.997$ (adjusted $R$ Squared $=0.995)$.

(4) Creep curve observes the Zhou model trend. Predicted strain calculated by Zhou model is similar to measured strain.

(5) Based on Zhou model, length of first stage of creep curve increased considerably in rubberized mixtures.

\section{Conflict of Interests}

The authors declare that there is no conflict of interests regarding the publication of this paper.

\section{Acknowledgments}

The authors would like to acknowledge the Department of Civil Engineering, Faculty of Engineering, University of Malaya, Kuala Lumpur, Malaysia, for providing the laboratory facilities to perform this study. This investigation is a part of the research supported by University of Malaya through Grant RP 010A-13SUS.

\section{References}

[1] ATJ 5/85, "Manual for the structural design of flexible pavement," Jabatan Kerja Raya Malaysia, 2013.

[2] N. S. Mashaan and M. R. Karim, "Evaluation of permanent deformation of CRM-reinforced SMA and its correlation with dynamic stiffness and dynamic creep," The Scientific World Journal, vol. 2013, Article ID 981637, 7 pages, 2013.

[3] N. S. Mashaan, A. H. Ali, S. Koting, and M. R. Karim, "Performance evaluation of crumb rubber modified stone mastic asphalt pavement in Malaysia," Advances in Materials Science and Engineering, vol. 2013, Article ID 304676, 8 pages, 2013.

[4] N. S. Mashaan, M. R. Karim, M. Abdel Aziz, M. R. Ibrahim, H. Y. Katman, and S. Koting, "Evaluation of fatigue life of CRMreinforced SMA and its relationship to dynamic stiffness," The Scientific World Journal, vol. 2014, Article ID 968075, 11 pages, 2014.

[5] G. Yadollahi and H. Sabbagh Mollahosseini, "Improving the performance of Crumb Rubber bitumen by means of Poly Phosphoric Acid (PPA) and Vestenamer additives," Construction and Building Materials, vol. 25, no. 7, pp. 3108-3116, 2011.
[6] H. Liu, Z. Chen, W. Wang, H. Wang, and P. Hao, "Investigation of the rheological modification mechanism of crumb rubber modified asphalt (CRMA) containing TOR additive," Construction and Building Materials, vol. 67, part B, pp. 225-233, 2014.

[7] Evonik Degussa GmbH, http://www.vestenamer.com/sites/dc/ Downloadcenter/Evonik/Product/VESTENAMER/en/brochures/VESTENAMER\%20Asphalt\%20english.pdf.

[8] K. E. Kaloush and M. W. Witczak, "Tertiary flow characteristics of asphalt mixtures," Journal of the Association of Asphalt Paving Technologists, vol. 71, pp. 248-280, 2002.

[9] L. P. T. L. Fontes, G. Trichês, J. C. Pais, and P. A. A. Pereira, "Evaluating permanent deformation in asphalt rubber mixtures," Construction and Building Materials, vol. 24, no. 7, pp. 11931200, 2010.

[10] F. Zhou, T. Scullion, and L. Sun, "Verification and modeling of three-stage permanent deformation behavior of asphalt mixes," Journal of Transportation Engineering, vol. 130, no. 4, pp. 486494, 2004.

[11] R. C. West, J. Zhang, and L. A. Cooley, "Evaluation of the asphalt pavement analyzer for moisture sensitivity testing," National Center for Asphalt Technology (NCAT) report 04-04, Auburn University, Auburn, Ala, USA, 2004.

[12] A. Khodaii and A. Mehrara, "Evaluation of permanent deformation of unmodified and SBS modified asphalt mixtures using dynamic creep test," Construction and Building Materials, vol. 23, no. 7, pp. 2586-2592, 2009.

[13] A. Mehrara and A. Khodaii, "Evaluation of asphalt mixtures' moisture sensitivity by dynamic creep test," Journal of Materials in Civil Engineering, vol. 23, no. 2, pp. 212-219, 2011.

[14] T. Baghaee Moghaddam, M. Soltani, and M. R. Karim, "Evaluation of permanent deformation characteristics of unmodified and Polyethylene Terephthalate modified asphalt mixtures using dynamic creep test," Materials and Design, vol. 53, pp. 317324, 2014.

[15] K. E. Kaloush, M. W. Witczak, and G. B. Way, Performance Evaluation of Arizona Asphalt Rubber Mixtures Using Advanced Dynamic Material Characterization Tests, Department of Civil and Environmental Engineering, College of Engineering and Applied Sciences, Arizona State University, 2002.

[16] REAM SP 4/2008 Specification for Polymer Modified Asphaltic Concrete, Road Engineering Association of Malaysia, 2008. 
[17] ASTM D5-13, Standard Test Method for Penetration of Bituminous Materials, American Society for Testing and Materials, 2004.

[18] ASTM, "Standard test method for softening point of bitumen (ring-and-ball apparatus)," ASTM D36-14el, American Society for Testing and Materials, 2004.

[19] ASTM D4402-13 Standard Test Method for Viscosity Determination of Asphalt at Elevated Temperatures Using a Rotational Viscometer, American Society for Testing and Materials, 2006.

[20] B. Burns, "Rubber-modified asphalt paving binder," U.S. Patent no. 5,936,015, 1999.

[21] M. Solaimanian, D. Anderson, and D. Hunter, Evaluation of Vestenamer Reactive Modifier in Crumb Rubber Asphalt, Pennsylvania Transportation Institute, 2003.

[22] K. L. N. Ng Puga, Rheology and performance evaluation of polyoctenamer as asphalt rubber modifier in hot mix asphalt [M.S. thesis], Iowa State University, 2013.

[23] S. Gokhale, B. Choubane, T. Byron, and M. Tia, "Rut initiation mechanisms in asphalt mixtures as generated under accelerated pavement testing," Transportation Research Record, no. 1940, pp. 136-145, 2005.

[24] G. Yadollahi and H. Sabbagh Mollahosseini, "Improving the performance of Crumb Rubber bitumen by means of Poly Phosphoric Acid (PPA) and Vestenamer additives," Construction and Building Materials, vol. 25, no. 7, pp. 3108-3116, 2011.

[25] G.-P. He and W.-G. Wong, "Laboratory study on permanent deformation of foamed asphalt mix incorporating reclaimed asphalt pavement materials," Construction and Building Materials, vol. 21, no. 8, pp. 1809-1819, 2007.

[26] G.-P. He and W.-G. Wong, "Effects of moisture on strength and permanent deformation of foamed asphalt mix incorporating RAP materials," Construction and Building Materials, vol. 22, no. 1, pp. 30-40, 2008. 

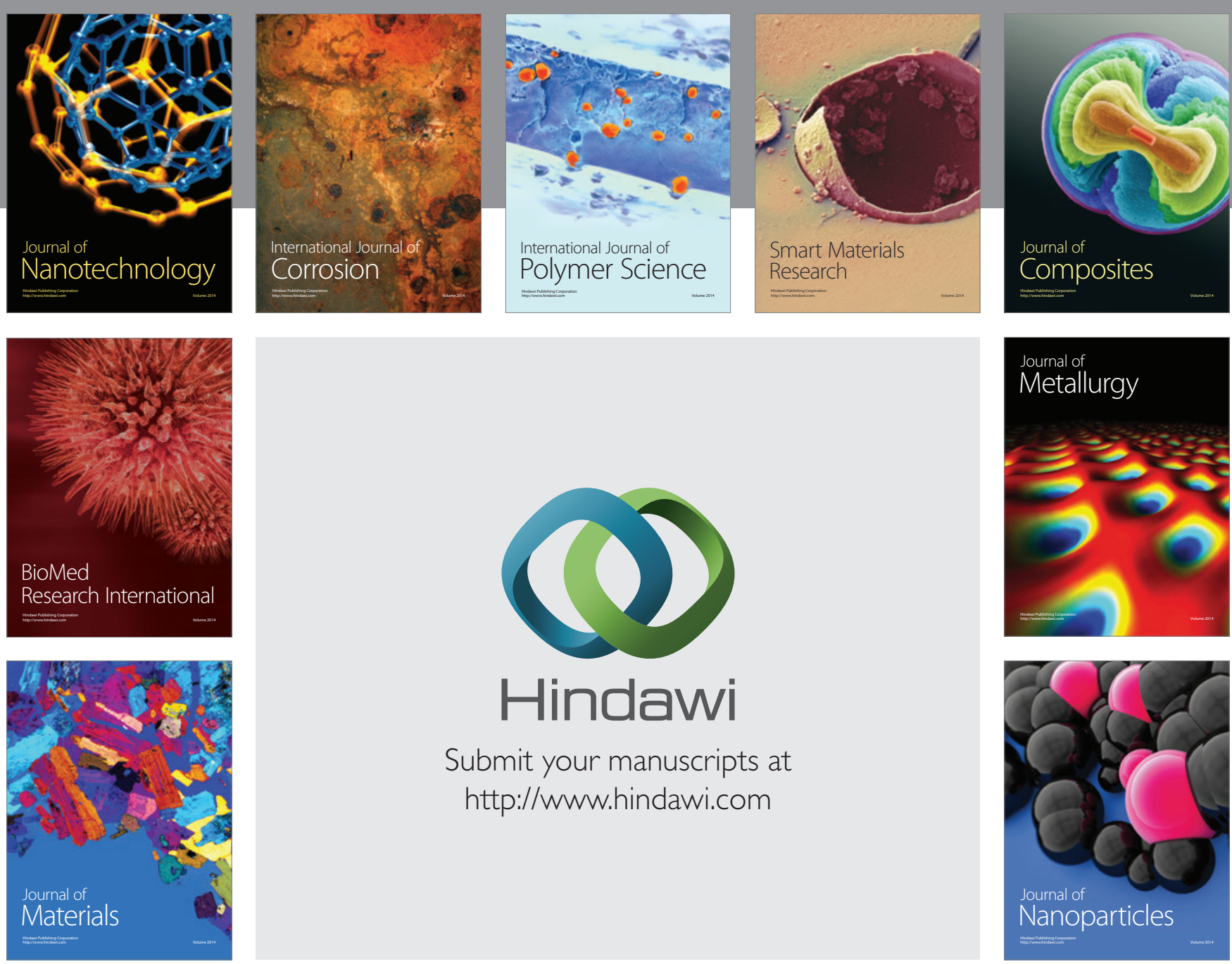

Submit your manuscripts at http://www.hindawi.com
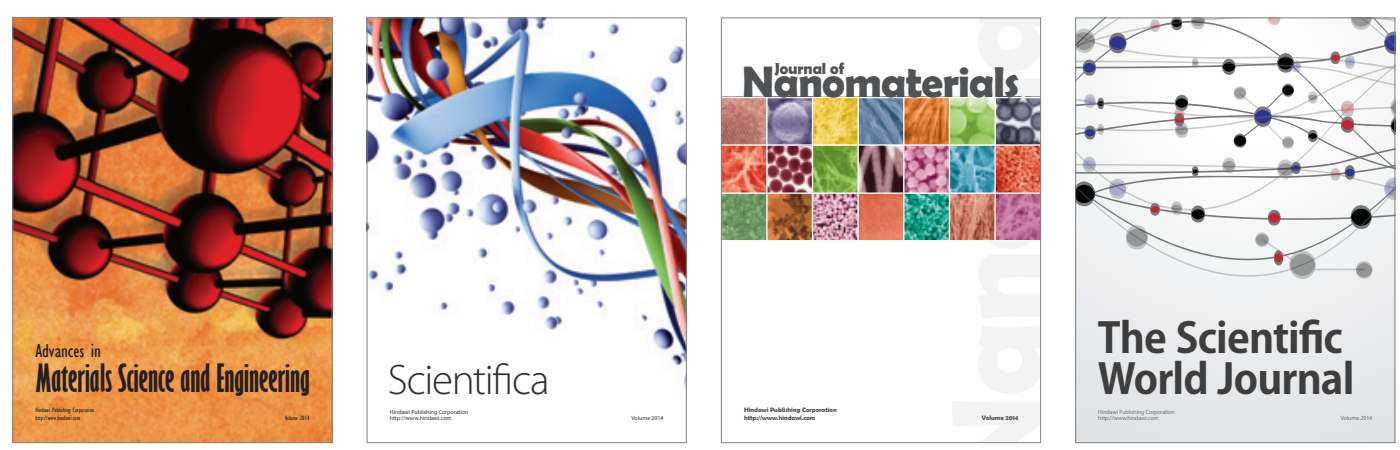

\section{The Scientific World Journal}
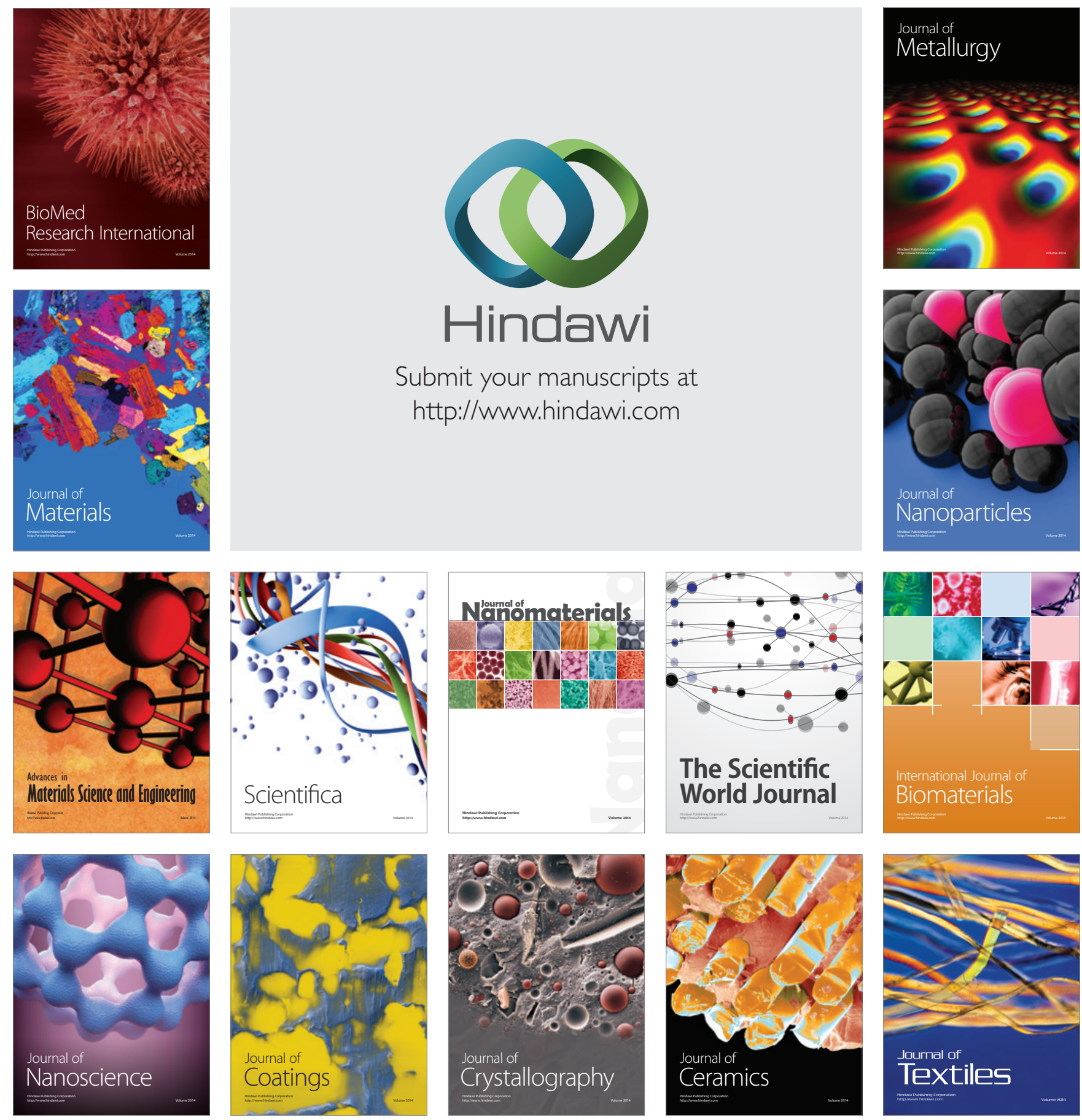